EGU2020-18239

https://doi.org/10.5194/egusphere-egu2020-18239

EGU General Assembly 2020

(c) Author(s) 2022. This work is distributed under

the Creative Commons Attribution 4.0 License.

\title{
An MSE budget view on seasonal and CO2-induced ITCZ shifts in the TRAC-MIP model ensemble
}

\author{
Elzina Bala ${ }^{1}$, Aiko Voigt ${ }^{1,2}$, and Peter Knippertz ${ }^{1}$ \\ ${ }^{1}$ Karlsruhe Institute of Technology (KIT), Institute of Meteorology and Climate Research, Troposphere, Germany \\ (elzinabala@gmail.com) \\ ${ }^{2}$ Lamont-Doherty Earth Observatory, Columbia University, New York, New York, USA
}

One of the grand challenges of climate is predicting and modeling tropical rainfall. Here, we address a specific problem of this grand challenge, namely how does the vertical structure of the atmosphere affect the tropical circulation and the position of the ITCZ during the seasonal cycle and in response to increased $\mathrm{CO}_{2}$. The tropical circulation can be described by the columnintegrated budget of moist static energy (MSE). We use this framework in the TRAC-MIP model ensemble to investigate the role of the vertical structure of the tropical atmosphere in setting the anti-correlation between the ITCZ location and the atmospheric energy transport.

TRACMIP "The Tropical Rain belts with an Annual cycle and Continent - Model Intercomparison Project" is a set of idealized simulations that are designed to study the tropical rain belt response to past and future forcings. TRACMIP includes 13 comprehensive CMIP5-class atmosphere models and one simplified atmospheric model. Importantly, TRACMIP includes a slab ocean with prescribed ocean heat transport. This leads to a closed surface energy balance and forces the annual-mean ITCZ to be north of the equator, consistent with today's climate.

We use the MSE budget framework to diagnose the seasonal evolution of vertical velocity from the energetic terms in the MSE budget equation. We obtain a diagnostic expression for the vertical velocity. By means of the MSE budget framework we estimate the efficiency of exporting energy from the atmospheric column, which is defined as the gross moist stability (GMS). The GMS characterizes the stability of the tropical troposphere related to moist convective processes in the tropospheric column. We use the MSE and GMS analysis to disentangle the impact of deep and shallow circulations on energy transport, vertical velocity and hence precipitation in an objective manner.

Through this work we aim to elucidate to what extent model uncertainty in simulations of future ITCZ changes are caused by model differences in the vertical structure of the atmosphere. We also hope to use the results to advance our understanding of the tropical climate and to assess the plausibility of simulated changes in tropical rainfall. 